Pagé MG, Ziegman D, Martel MO, Shir Y. (2019) Development and validation of the treatment expectations in chronic pain scale. British Journal of Health Psychology; 24(3): 610-628. Doi: 10.1111/bjhp.12371. PMID: 30989756 


\title{
Development and Validation of the Chronic Pain Treatment Expectations Questionnaire
}

\author{
Pagé $\mathrm{MG}^{1,2,3}$, Ziemianski $\mathrm{D}^{3}$, Martel $\mathrm{MO}^{3,4,5}$, Shir $\mathrm{Y}^{3,5}$ \\ ${ }^{1}$ Centre de recherche du Centre hospitalier de l'Université de Montréal (CRCHUM), \\ Montreal, QC, Canada \\ ${ }^{2}$ Department of anesthesiology and pain medicine, Faculty of Medicine, Université de \\ Montréal, Montreal, QC, Canada \\ ${ }^{3}$ Alan Edwards Pain Management Unit, Montreal General Hospital, Montreal, QC, \\ Canada \\ ${ }^{4}$ Faculty of Dentistry, McGill University, Montreal, QC, Canada \\ ${ }^{5}$ Department of Anesthesia, Faculty of Medicine, McGill University, Montreal, QC, \\ Canada
}

Corresponding author:

MG Pagé, $\mathrm{PhD}$

Centre de recherche du Centre hospitalier de l'Université de Montréal (CRCHUM) 850 rue St-Denis, office S01-112, Tour Saint-Antoine

Montreal, QC, Canada H2X 0A9

Tel: (514) 890-8000 ext. 31601

gabrielle.page@umontreal.ca

Funding source: The Louise and Alan Edwards Foundation, Montreal, Canada

Acknowledgments: The authors would like to thank Sylvie Toupin for her assistance with data collection and data entry. 


\begin{abstract}
Objectives. To develop and examine the psychometric properties of the Chronic Pain Treatment Expectations Scale (COPTES), a brief measure of treatment expectations of chronic non-cancer pain treatment.
\end{abstract}

Design. A cross-sectional study design was used.

Methods. After conducting a literature review and expert discussions, a preliminary version of the COPTES was developed. Cognitive interviews with 10 clinicians and 14 patients were conducted to examine the scale's face validity and item wording. Last, two hundred and five patients on the waitlist for a multidisciplinary pain treatment center completed a battery of self-report questionnaires to examine the COPTES' reliability and construct validity. Mokken scale analysis was conducted to select the final items. Reliability (Cronbach's alpha, Guttman's Lambda ${ }^{2}$ and McDonald's omega) and construct validity (Pearson correlations) were assessed.

Results. The final scale was composed of nine items that each measured ideal and realistic expectations about process and outcome of treatment. Mokken scale analysis showed the presence of two subscales: ideal and realistic expectations. The COPTES had good internal consistency ( $\alpha=0.876-0.869)$ and adequate discriminant validity as assessed by its low correlation with measures of depression, anxiety and quality of life ( $r$ $=-0.038-0.114)$. The scale had however low correlation with a theoretically related measure of optimism $(r=0.240)$.

Conclusion. The COPTES is a reliable scale measuring pain treatment expectation.

Further evaluation of its psychometric properties is needed. The scale has the potential to deepen our understanding of the role treatment expectations play in chronic non-cancer pain treatment response. 


\section{Development and Validation of the Treatment Expectations in Chronic Pain Scale}

\section{Statement of Contribution}

What is already known on this subject?

- Expectations play a role in pain perception and the response to pain treatment

- Patients' expectations about pain and its management are associated with treatment satisfaction

- The absence of a validated tool to measure treatment expectations in chronic noncancer pain prevents further exploration and understanding of the role of expectations in the context of multidisciplinary pain treatment

What does this study add?

- A new, reliable 9-item scale measuring treatment expectations among chronic non-cancer pain patients attending specialized multidisciplinary pain clinics 
Chronic non-cancer pain (CNCP) is a complex multidimensional experience defined by the presence of pain that continues despite typical tissue healing time (3 or 6 months), or pain which is associated with a progressive non-malignant disease (Pain, 1986). About $20 \%$ of adult Canadians suffer from CNCP (Boulanger, Clark, Squire, Cui, \& Horbay, 2007; Schopflocher, Taenzer, \& Jovey, 2011). This condition has detrimental physical, psychological and social functioning consequences and contribute to deteriorated quality of life (Choiniere et al., 2010; Jonsdottir, Aspelund, Jonsdottir, \& Gunnarsdottir, 2014; Langley et al., 2010).

\section{Determinants of CNCP Treatment Response}

Given the multidimensionality of the pain experience, multidisciplinary approaches are considered the gold standards for treating CNCP (Flor, Fydrich, \& Turk, 1992; International Association for the Study of Pain, 1990). Key ingredients (pharmacological and non-pharmacological interventions, therapeutic alliance, treatment beliefs) associated with clinically significant $\mathrm{CNCP}$ treatment responses however have yet to be clearly delineated (Beasley, Ferguson-Jones, \& Macfarlane, 2017). Research is increasingly showing that expectations might be one such key ingredient that affect $\mathrm{CNCP}$ treatment response.

\section{Role of Expectations in Treatment Response}

Expectation (as understood through social learning theory) refers to the complex interplay of thoughts, values and beliefs that are formed through past experiences and that represent an evaluation of anticipated outcomes specific to a situation (Kravitz, 1996; Rotter, 1954, 1982). Four types of expectations have been proposed: ideal (desires and outcome preferences), predicted (outcomes that one expect); normative (what one thinks should 
happen), and unformed (unarticulated) (Thompson \& Sunol, 1995). Numerous studies have shown the importance of expectations in the pain experience, especially in the context of analgesic properties of placebo (Peerdeman et al., 2016): expecting pain reduction is typically associated with decreased pain intensity and improved treatment outcomes (Gandhi, Davey, \& Mahomed, 2009; Linde et al., 2007). In contrast, expecting increased pain is associated with increased pain reports (Colloca \& Grillon, 2014).

The role of expectations in the treatment of complex, severe CNCP can also influence treatment response. Indeed, like many other chronic conditions, $\mathrm{CNCP}$ is often not curable. Treatment goals are typically geared toward reducing suffering, improving functioning and quality of life as opposed to curing pain. Levels of engagement in one's treatment plan could thus be greatly influenced by expectations. Expecting that $\mathrm{CNCP}$ will be completely cured as a result of treatment might pose barriers to engagement in psychological and physiotherapy approaches that aim to improve functioning and quality of life. Distinguishing between ideal and predicted expectations might be particularly relevant. One study has shown that the degree of discrepancy between ideal and predicted expectations was associated with continued use of health care resources (Robinson et al., 2005). Assessing both ideal and predicted expectations could also help guide interventions geared at setting realistic treatment expectations.

A recent study of chronic pain patients attending a multidisciplinary pain treatment facility showed that patients' pre-treatment expectations were significantly associated with changes in treatment outcomes from baseline to 6 months (pain intensity, depressive symptoms, pain interference, pain catastrophizing, satisfaction with treatment), and this relationship was mediated by patients' global impression of change (Cormier, Lavigne, 
Choinière, \& Rainville, 2016). Despite this evidence demonstrating an association between treatment expectations, treatment satisfaction and treatment responses in pain populations, little is known about factors that modify expectations and in turn improve satisfaction and CNCP treatment outcomes.

\section{Operationalization of Expectations}

In the context of medical treatments, the content of expectations has been shown to have three specific dimensions, namely structure, process and outcomes (Kravitz, 1996). Structure refers to the physical environment, staff, and organizations necessary to offer adequate health care. Process refers to the perceived abilities of clinicians to provide the health care and includes interpersonal skills and competence. Outcomes refer to the results expected from the health encounter in terms of physical health and psychosocial factors. While structure is an important dimension of expectations, it is also one that is the least replicable across treatment settings (Kravitz, 1996). As such, most studies have focused on outcome-related expectations and a small minority on a combination of process and outcome expectations (Geurts et al., 2017).

Expectations share substantial similarities with other cognitive constructs, such as optimism. Optimism refers to the favorable perceptions of a future outcome based on past experiences (Bryant \& Harrison, 2015b). Thus a CNCP patient who is optimistic might have highly favorable expectations of treatment outcome. These two related constructs have an important distinction however in that the former is influenced by beliefs in one's personal responsibility for achieving the expected positive outcome whereas the latter does not make such attribution (Bryant \& Harrison, 2015b). 
While expectations can influence treatment outcomes and vice-versa (e.g., depressive symptoms can lead to dysfunctional expectations that are not being updated despite new evidence), it is a construct quite different from other psychological experiences such as depression and anxiety (Kube, Rief, \& Glombiewski, 2017). Depression and anxiety both include cognitive components that could be influencing and influenced by expectations. However they represent a much wider set of symptoms that also include emotional and physical components.

\section{Lack of Validated Expectation Measure for CNCP Multidisciplinary Treatment}

One element that can explain the lack of mechanistic understanding of the role expectations play in pain $\mathrm{CNCP}$ treatment is the absence of a validated measure of expectations designed specifically for $\mathrm{CNCP}$ patients. In a recent systematic review, van Hartingsveld and colleagues (2010) examined available questionnaires to measure expectations in musculoskeletal disorders based on patient (self-efficacy) and treatment (process and outcomes) expectations. The authors found $3 \mathrm{CNCP}$-specific expectation questionnaires ((Anderson, Dowds, Pelletz, Edwards, \& Peeters-Asdourian, 1995; Nicholas, 2007; Robinson et al., 2005)), but all of these scales measured patient expectations or selfefficacy and not treatment expectations (van Hartingsveld et al., 2010). A second systematic review specifically on expectation measures among CNCP patients found that not all dimensions of expectations are systematically taken into account (Geurts et al., 2017). Outcome expectations are the most frequently measured while structure and process expectations are under-represented. Authors also found important differences between patients' hopes of therapeutic outcome (ideal expectations) versus predicted expectations that are often not captured in questionnaires. 


\section{Objectives and Hypotheses}

A validated tool to measure $\mathrm{CNCP}$ patients' expectations is required in order to elucidate factors that modify pain treatment expectations. A validated questionnaire will assist with the systematic quantitative evaluation of the impact of processes and interventions on CNCP patients' expectations.

The current study outlines a systematic multi-phase process to develop and validate a CNCP patient expectation questionnaire. We anticipated that the Treatment Expectations in Chronic Pain (TEC) scale will have face, convergent (moderate-high correlation with a measure of optimism) and divergent (low correlation with unrelated measures of depression, anxiety and quality of life) validity as well as reliability. We expect that this scale will have a two-factor solution comprised of predicted and ideal treatment expectation scores. 


\section{Methods}

The study was approved by the Institutional Review Board of the XXX.

\section{Development of the Treatment Expectations in Chronic Pain scale}

Item Generation. The development and validation of this new questionnaire was an iterative multi-step process modeled on the Patient-Reported Outcome Measurement Information System (PROMIS) questionnaire development guidelines (http://www.nihpromis.org) (PROMIS Validity Standards Committee on behalf of the PROMIS Network of Investigators, 2012).

A literature review was conducted to identify relevant existing questionnaires (Patient Expectations Questionnaires (Bowling \& Rowe, 2014), Patient Centered Outcome Questionnaire (Robinson et al., 2005), Credibility/Expectancy Questionnaire (Devilly \& Borkovec, 2000)). Existing questionnaire items, as well as other items based on experts' knowledge were then adapted as needed to assess chronic pain patients' expectations. This pool of potential items $(n=36)$ was then reviewed by three pain experts to assess face validity and item clarity, precision, applicability, and redundancy. Content was assessed for a target Grade 6 reading level (fluent, but not advanced, reading skills) by the research team. This iterative process led to the preliminary version of the TEC scale that contained 19 items (see Table 1). Items included in this preliminary scale included both process and outcome-related expectations; the process expectation items were not included as to ensure that the scale can be used across CNCP treatment settings. Similar to the Patient Expectations Questionnaire (Bowling \& Rowe, 2014), the questionnaire was designed to ask patients to rate their expectations in terms of both their ideal (what they ideally hope 
will happen) as well as their predicted (what they expect to happen in real life) expectations.

Patient and clinician interviews. Feedback was gathered from experts and patients for both construct definition and item selection. Written and verbal feedback from clinicians specialized in CNCP multidisciplinary treatment was gathered on the face validity of the scale (how the items relate to the definitions of process and outcome treatment expectations; understanding of the ideal and predicted expectations) and item wording. Individual interviews were conducted with $\mathrm{CNCP}$ patients attending multidisciplinary pain treatment clinics. The interview consisted of open-ended questions evaluating the questionnaire for item relevance and understanding. Interviews were conducted until data saturation, namely the point at which no original feedback was being received. Patients were selected to ensure representativeness of the patient population in terms of age, sex, education level, ethnicity and pain condition.

Final item selection process and evaluation of the scale's psychometric properties. The preliminary version of the TEC scale was administered to a large sample of CNCP patients, as described in the Procedure and Data Analysis sections below.

\section{Procedure - Item Selection and Evaluation of Scale's Validity and Reliability}

Final item selection was data-driven. Participants were recruited from the waitlist of a tertiary multidisciplinary pain treatment center. Upon receiving their referral, patients were invited to a mandatory orientation session as part of the routine clinical process during which they learned about the clinic's procedure and provided complementary information used for triage purposes. Patients attending these sessions received in the mail two weeks before their orientation session a letter describing the research study along with the 
informed consent form and study questionnaires to return to the clinic at their orientation session.

\section{Participants}

Eligible participants were 1) aged 18 years or older, 2) fluent in written English, 3) and referred to a multidisciplinary pain treatment center. Only patients invited to the orientation session were invited to participate. Patients are not required to attend the clinic's orientation session if they are living more than $150 \mathrm{~km}$ from the pain center, are above 80 years of age and/or have significant physical limitations. As such these individuals could not be recruited as part of this study.

\section{Measures}

Treatment Expectations in Chronic Pain TEC Scale. The TEC scale is a selfreport questionnaire measuring patients' ideal and predicted expectations. Items are designed to measure two aspects of expectations, namely process and outcome expectations. Instructions are as follow: "The following questions are about your expectations of the treatment you will receive for your chronic pain. For each question, please check the box that best corresponds to (a) what you ideally hope will happen (in a $\mathrm{n}$ ideal world, what would you want to happen) during your health care appointment(s) and (b) what you realistically expect will happen (in real life, what do you expect will actually happen) during your health care appointment). For each item, patients are asked to select the extent to which they agree with the statement on a 5-point scale $(1=$ strongly disagree, to $5=$ strongly agree) in terms of their ideal and predicted expectations. Each item is thus scored twice by participants. 
Patient Health Questionnaire-4 (PHQ-4). The PHQ-4 (Kroenke, Spitzer, Williams, \& Lowe, 2009) screens for depressive and anxiety symptoms using a 4-point Likert scale. The two depression items can be summed up with higher scores indicating higher levels of depressive symptoms. The same is true for the two anxiety items. The four items are also summed up to generate a composite score reflecting levels of psychological distress with the following classification: normal (0-2), mild (3-5), moderate (6-8) and severe (9-12). The PHQ-4 has been shown to have good validity (Kroenke et al., 2009).

Short-Form-12 Health Survey version 2 (SF-12v2). The SF-12v2 (Ware, Kosinski, \& Keller, 1996) is a 12-item questionnaire that produces norm-based physical and mental health-related quality of life scores. For each item, patients check the answer that best fits their condition, with answer types varying from one item to another. The questionnaire has good psychometric properties (Ware et al., 1996).

Life Orientation Test-Revised (LOT-R). The LOT-R (Scheier \& Carver, 1985; Scheier, Carver, \& Bridges, 1994) is a 10-item scale that measures patients' levels of optimism/pessimism. For each item patients are asked to rate the extent to which they agree with the statement $(0=$ strongly disagree to $4=$ strongly agree $)$. Four of the 10 items serve as filers. The scale has adequate validity and reliability.

\section{Statistical Analyses}

Item-response theory. The process of item reduction was carried out using Mokken Scale Analysis, a type of non-parametric item response theory using a monotone homogeneity model (Mokken, 1971). The monotone homogeneity model was selected over the double monotonicity model because of violations of the assumption of non-intersection of the item step response (see Supplementary Table 1) (Van der Ark, 2007). Items were 
screened for their psychometric qualities for inclusion in the final scale. This approach has less restrictive assumptions than parametric item response theory; assumptions of this model are unidimensionality (all items are related to one latent variable), monotonicity (probability of endorsing a response category based on the presence of the latent trait remains the same or increases the higher the value of the latent trait), and local independence (answers on items depend solely on the latent trait and not some other characteristics of the individual or its environment) (Van der Ark, 2007). The last assumption is only met in the analysis of the TEC when the subscales of predicted and ideal expectations are analyzed separately.

The analysis was carried out in 10 steps as recommended by Sijtsma and van der Ark (2017) using the R package Mokken (van der Ark, Straat, \& Koopman, 2018) in the statistical software R version 3.4.2 (R Core Team, 2017).

Data examination. Data was examined for missing data, inadmissible scores and outliers. Item correlations were also examined to identify redundant items. Items with $r>$ 0.60 were removed (Hinkle, 2003).

Scale identification. Items were examined for scalability ( $\mathrm{H}$ coefficient) and dimensionality using the Automated Item Selection Procedure (AISP). The scalability refers to the extent to which an item fits within the other scale items to order patients based on the degree to which they possess the scale's underlying latent trait. The coefficient H indicates an unscalable scale if $<0.3$, a weak scale if $0.3 \leq \mathrm{H}<0.4$, a medium scale if 0.4 $\leq \mathrm{H}<0.5$ and a strong scale if $0.5 \leq \mathrm{H} \leq 1.0$ (Mokken, 1971). This procedure was used to remove unscalable items $(\mathrm{H}<0.3)$. The AISP procedure was run for positive constant $c$ initially set at 0.25 and then re-run with $c$ increased by increments of 0.05 . Examination of 
the $\mathrm{H}$ coefficient at each of the $c$ value as well as number of suggested scales was used to confirm whether the TEC scale is comprised of one (global expectations) or two subscales (ideal and predicted expectations). Next, the issue of local independence was examined using the conditional association procedure. When item pairs were flagged for nonindependence, one of the items was removed from the scale. Monotonicity was examined using a non-parametric regression method to identify deviations from monotonicity; graphical analysis was used to visually examine monotonicity curves for each items.

Scale properties. Internal consistency was assessed using Cronbach's alpha $(0.7 \leq$ $\alpha<0.8$ is acceptable; $0.8 \leq \alpha<0.9$ is good; $0.9 \leq \alpha$ is excellent scale reliability (Kline, 2000)), Guttman's lambda-2 (Guttman, 1945) and Molenaar Sijtsma r.h.o. (Molenaar \& Sijtsma, 1984). McDonald's omega ( $\omega)$ was also used to examine the reliability of the ideal and predicted expectations separately. High hierarchical $\omega$ values $(>0.7)$ suggest unidimensionality of the subscales (Revelle \& Zinbarg, 2009). McDonald's omega was computed using the Psych package in R (Revelle, 2018). Group comparisons were also examined for males and females to determine whether scale composition and properties are generalizable across sex.

Construct validity. Convergent and divergent validity were assessed to examine the construct validity of the scale. Convergent validity (whether constructs that are theoretically related to each other are in fact observed as related to each other) was determined by examining the Pearson correlation coefficient between the TEC scale ideal and predicted expectations scores and a theoretically related, although somewhat distant, construct (optimism). A positive, moderate-to-high correlation coefficient $(r \geq 0.60$ (Hinkle, 2003)) would indicate adequate convergent validity. Discriminant validity 
(whether constructs that are theoretically unrelated to each other are in fact observed as unrelated to each other) was determined by examining the Pearson correlation coefficient between the TEC scale's ideal and predicted expectations and unrelated constructs, namely depressive symptoms, anxiety and quality of life. A low-to-moderate positive or negative correlation would support adequate discriminant validity $(r<0.50$ (Hinkle, 2003)). Correlations between the optimism, anxiety, depressive symptoms and quality of life scale and the difference in scores between the predicted and ideal expectation scores were also examined. This score represents the extent to which what they wish to happen is far from what they think will happen.

\section{Results}

\section{Questionnaire Development - Interviews with clinicians and patients}

Ten clinicians (2 anesthetists, 2 family doctors, 2 physiatrists, 1 psychologist, 1 physiotherapist, 1 nurse, 2 residents) working in a tertiary care multidisciplinary pain treatment provided written feedback on the preliminary version of the TEC scale. These clinicians had an average of $5.88 \pm 5.2$ years of experience; $60 \%$ were female. Their feedback was overall positive: $78 \%$ and $89 \%$ of clinicians believed the TEC scale measured the constructs of process and treatment expectations, respectively. Clinicians were asked to rate the scale overall in terms of its usefulness, importance, ease of administration, ease of response, reading level and length on a scale from 1 (very good) to 5 (very poor). Each of these items was on average rated as "good" (score of $2 / 5$ ). No changes were made to the number or content of included items at this stage although some wording changes were done. 
Fourteen CNCP patients completed interviews on the preliminary version of the TEC scale. These patients were primarily males (64\%) with a mean age of $51.0 \pm 12.0$ years. All but three patients suffered from pain in multiple body locations and had been suffering from pain for $16.0 \pm 14.0$ years on average. All patients reported understanding the difference between predicted and ideal expectations and made some wording suggestions to the instructions and items which were incorporated into the final preliminary version. No significant difficulties were reported with the completion of the questionnaire.

\section{Psychometric Evaluation of the TEC Scale}

Five hundred and twenty-two patients were approached to participate in the present study between October 2016 and February 2018. Two hundred ninety-one patients (55.7\%) declined participation or did not return the completed questionnaires. Two hundred thirtyone patients completed partially the questionnaires but 26 of them either did not return a signed consent form or completed less than $50 \%$ of the study questionnaires. Individuals who completed more than $50 \%$ of the study questionnaires were younger (mean age $=$ $51.67 \pm 17.7$ compared to $65.28 \pm 23.3$ for non-completers, $p=0.01$ ) and more likely to be Caucasian $(p<0.01)$. There were no sex differences between individuals who completed vs. did not complete all study questionnaires.

The final sample was composed of $205 \mathrm{CNCP}$ patients on the waitlist for a tertiary care multidisciplinary pain treatment center in the province of Quebec. Mean age was $51.67 \pm$ 17.7 years. The majority of patients identified as Caucasian (86.7\%) and the sample was

predominantly female (61.2\%). Forty percent of patients had completed university. Table 2 shows sample characteristics. 
Data Examination. There was less than $1 \%$ of missing data on the 19 items of the preliminary version of the TEC scale. Missing data was imputed using ExpectationMaximization approach (Lin, 2010). There was also one outlier based on total score on the TEC scale $\left(\chi^{2}=14.37, p<0.01\right)$ and as such this participant's data was removed.

Pearson correlation was used to identify items that are highly correlated $(r>0.60)$. Three items were identified as being highly correlated with $\geq 1$ other item and as such were removed from the scale (see Table 1 for details).

Scale Identification: Mokken Scale Analysis (Item-Response Theory). First, items were examined for their scalability. Five items were removed because they were unscalable $(\mathrm{H}<0.3)$ on either the ideal or the predicted score (see Table 1). AISP was used to examine the dimensionality of the scale. When $\mathrm{c}$ was set to 0.25 or 0.30 , all items were classified into one single dimension. At $\mathrm{c}=0.35$, two dimensions emerged in which all 'ideal' scores formed one dimension and all 'predicted' scores formed a second dimension (see Supplementary Table 2). As such, the items were separated into two distinct subscales representing ideal and predicted expectations. Next, the issue of local independence was examined. Three pairs of items were flagged as non-independent (items 12 with 18, 12 with 17 and 13 with 18). Experts (MGP, YS, MM) reviewed these items and two items with the lowest $\mathrm{H}$ value were removed (see Table 1). Monotonicity was examined subsequently. There were no significant item violations of monotonicity on either the ideal or the predicted subscales. Finally, the $\mathrm{H}$ coefficient was then re-examined for the two subscales separately $(\mathrm{H}=0.476$ for the predicted expectations subscale and $\mathrm{H}=0.482$ for the ideal expectations subscale). Results are presented in Supplementary Table 2. All items had H > 0.3 . 
The final scale was thus comprised of nine items, yielding 18 ratings (each item is rated in terms of ideal and predicted expectations) and two subscale scores. Five of the nine items measures aspects of outcome expectations (pain reduction, improved functioning, diagnosis, mood and sleep) and the remaining four items measure aspects of process expectations (treatment plan, education about pain management, increased knowledge of one's condition and understanding from pain specialist).

Scale Properties. Scale properties, including distribution of scores for each subscale is presented in Table 3. Some ceiling effect was noticed for the ideal subscale items, with $60 \%-70 \%$ of patients selecting the highest score. This was not the case for the predicted expectation items. Items from the ideal expectation subscale were systematically scored higher (4 ("agree") to 5 ("strongly agree")) than their counterpart in the predicted expectation subscale (3 ("neither agree nor disagree") to 4 ("agree")). Corrected item-total correlation, Cronbach's alpha and Guttman's lambda ${ }^{2}$ are shown in Table 4. For the ideal and predicted expectations subscales, $\alpha=0.876$ and 0.869 , respectively. Reliability did not improve when any one item was deleted from the scale $(\alpha=0.835-0.871)$.

McDonald's omega was calculated separately for the ideal $\left(\omega_{\mathrm{h}}=0.91 ; \omega_{\mathrm{t}}=0.91\right)$ and predicted $\left(\omega_{\mathrm{h}}=0.88 ; \omega_{\mathrm{t}}=0.88\right)$ subscales with adequate reliability.

Construct Validity. Neither the ideal nor the predicted expectations subscales or the difference between predicted and ideal expectation scores of the TEC scale correlated highly with a measure of optimism ( $r=-0.240$ for predicted expectations; $r=-0.061$ for ideal expectations; $r=0.208$ for the difference score). However both the ideal $(r=-0.038-$ $0.092)$ and predicted $(r=-0.139-0.114)$ expectations subscales had negative and low 
correlations with measures of depression, anxiety, and quality of life. Results of these correlation analyses are shown in Table 5. 


\section{Discussion}

The present study aimed to develop a new scale to measure CNCP patients' treatment expectations. Literature review, expert discussions, and feedback from clinicians in pain medicine and CNCP patients led to a preliminary 19-item scale. Pearson correlation and Mokken scale analysis were used to select the final set of 9 items. There is preliminary evidence of reliability and validity but these results must be interpreted with caution. The construct validity was only partially confirmed and predictive validity was not evaluated.

\section{Structure of the TEC Scale}

Mokken scale analysis was used to select final scale items. This is a probabilisticnonparametric approach in the family of item response theory that is used to examine measurement properties of a scale with less strict assumptions. This analysis was exploratory in nature and the first step in the stages of scale development. Validation in large multi-center studies and with various CNCP populations across primary, secondary and tertiary care settings are needed (Bowling et al., 2012).

Multidimensionality of the scale was demonstrated, suggesting that the calculation of a total score of the TEC scale (summing all items across ideal and predicted scores) is not valid. Rather, a total score should be computed separately for the ideal expectation items and predicted expectation items. This is even more important considering that the assumption of local independence of Mokken scaling analysis is only satisfied if the ideal and predicted expectations are treated as different scale.

Results showed that all items representing ideal expectations (process and treatment expectations) formed a single unidimensional construct; the same was true for the predicted expectation items. This suggests that individuals have similar expectations across these two 
domains of expectations (which outcomes will improve after treatment and the way this treatment will be delivered). There is a paucity of literature on process expectations as they related to $\mathrm{CNCP}$ treatment. In a systematic review of patient expectations for management of $\mathrm{CNCP}$, only 4 of 23 papers found examined process expectations; the vast majority examined treatment outcome expectations $(n=21)$ (Geurts et al., 2017). These dimensions of expectations are not examined together in the literature and as such it is unclear whether they have a different contributions to treatment outcome, satisfaction or other treatmentrelated responses. Results of the current TEC scale analysis support the computing of a score that includes process and treatment outcome expectations; this should be further explored and validated in other patient cohorts.

\section{Reliability}

All indicators examined showed that the scale has good internal consistency. Deletion of any single item did not significantly improve the internal consistency of the scale. All subscales demonstrated adequate scalability suggesting the presence of underlying constructs (ideal and predicted expectations). For both subscales, $\omega_{\mathrm{t}}$ was approximately 0.90. This suggests that for each subscale approximately $90 \%$ of the variance in the subscale score is accounted for by the underlying latent construct (Revelle \& Zinbarg, 2009).

\section{Validity}

The scale was uncorrelated with measures theoretically expected to be unrelated. This provides preliminary support for the divergent validity of the scale. As such, no linear relationship could be found between these constructs. It is possible that depressive and anxiety symptoms influence expectations to different degrees based on their severity, or 
indirectly through the loss of hope or external locus of control typically associated with depression (Campbell, Hope, \& Dunn, 2017). Further exploration of the relationship between these constructs is warranted.

Unexpectedly, the scale demonstrated poor convergence validity as assessed by the correlation between the TEC and a measure of optimism (LOT-R). It is possible that the construct of optimism is not sufficiently related to expectations and as such does not represent an optimal construct to assess convergent validity. It is also possible that the results is due to the non-pain specificity of the LOT-R. This optimism scale has been primarily used in the general population and not validated in clinical populations such as CNCP patients. It will be essential to continue examining the convergence validity of the TEC scale using alternative constructs related to pain treatment expectations, such as patients' beliefs about pain or patients' intentions. It is also possible that the low convergent validity observed is due to the population studied. Patients referred to specialized, tertiary care centers have often a long history of poorly managed pain or pain unresponsive to treatment. Their particular treatment path might have contributed to a polarization of their expectations. Indeed, expectations are partly shaped through past experiences (Kravitz, 1996; Rotter, 1954, 1982). Some individuals might have reduced their expectations because of repeated treatment failures. For others, presence of persistent, severe pain might lead them to perceive a specialized treatment center as their last hope for cure. If such polarization is present, it could influence the association of the TEC scale scores with other related constructs such as optimism.

\section{Study Limitations}


There are some study limitations. First, and perhaps most importantly, it is possible that procedure for item selection is dependent on the dataset used. This is due to $\mathrm{H}$ values being overestimated in some items and underestimated in other items, per chance, compared to their true values. This tends to favor inclusion of some overestimated items. As such, external validation of the TEC is necessary. Second, the study design was cross-sectional and as such some psychometric properties of the scale were not evaluated (predictive validity, test-retest reliability). Third, the study did not evaluate whether the questionnaire's structure differs across sex, cultures or pain conditions given the limited sample size.

\section{Future Research Directions}

Results show that the TEC scale is a reliable questionnaire to evaluate patients' ideal and predicted expectations of $\mathrm{CNCP}$ treatment in the context of multidisciplinary pain treatment. Convergent validity was suboptimal in the present study and as such it will be important to further evaluate the psychometric properties of the TEC scale in different populations and using alternative constructs against which to examine convergent validity. Stability of the construct over time, predictive validity and sensitivity to change following interventions targeting patients' expectations should also be assessed in longitudinal studies. Further exploration of the association between process and outcome expectations and whether they make significant independent contributions to treatment response would make significant contributions to this field of research.

In conclusion, the study provides evidence for the bidimensionality of patients' expectations (ideal and predicted) scale that could be used in research and clinical settings. Indeed, this new questionnaire will allow for the examination of the association between patients' expectations and treatment (treatment response, treatment satisfaction, 
engagement in self-management) and administrative outcomes (attendance to scheduled appointments). Identification of determinants of patients' expectations could lead to the design of interventions aimed at modulating expectations to improve outcomes. 


\section{References}

Anderson, K. O., Dowds, B. N., Pelletz, R. E., Edwards, W. T., \& Peeters-Asdourian, C. (1995). Development and initial validation of a scale to measure self-efficacy beliefs in patients with chronic pain. Pain, 63(1), 77-84.

Beasley, M. J., Ferguson-Jones, E. A., \& Macfarlane, G. J. (2017). Treatment expectations but not preference affect outcome in a trial of CBT and exercise for pain. Canadian Journal of Pain, 1(1), 161-170.

Boulanger, A., Clark, A. J., Squire, P., Cui, E., \& Horbay, G. L. (2007). Chronic pain in Canada: have we improved our management of chronic noncancer pain? Pain Res Manag, 12(1), 3947.

Bowling, A., \& Rowe, G. (2014). Psychometric properties of the new Patients' Expectations Questionnaire. Patient Experience Journal, 1(1), 111-130.

Bowling, A., Rowe, G., Lambert, N., Waddington, M., Mahtani, K. R., Kenten, C., . . Francis, S. A. (2012). The measurement of patients' expectations for health care: a review and psychometric testing of a measure of patients' expectations. Health Technol Assess, 16(30), i-xii, 1-509. doi:10.3310/hta16300

Bryant, F. B., \& Harrison, P. R. (2015a). Measures of Hope and Optimism: Assessing Positive Expectations of the Future. In G. J. Boyle, D. H. Saklofske, \& G. Matthews (Eds.), Measures of Personality and Social Constructs (pp. 47-73). Boston, USA: Academic Press.

Bryant, F. B., \& Harrison, P. R. (2015b). Measures of hope and optimism: Assessing positive expectations of the future. In G. J. Boyle, D. H. Saklofske, \& G. Matthews (Eds.), Measures of Personality and Social Psychological Constructs (pp. 47-73). Amsterdam, Netherlands: Elsevier/Academic Press.

Campbell, P., Hope, K., \& Dunn, K. M. (2017). The pain, depression, disability pathway in those with low back pain: a moderation analysis of health locus of control. J Pain Res, 10, 2331-2339. doi:10.2147/JPR.S139445

Choiniere, M., Dion, D., Peng, P., Banner, R., Barton, P. M., Boulanger, A., ... Ware, M. (2010). The Canadian STOP-PAIN project - Part 1: Who are the patients on the waitlists of multidisciplinary pain treatment facilities? Can J Anaesth, 57(6), 539-548. doi:10.1007/s12630-010-9305-5

Colloca, L., \& Grillon, C. (2014). Understanding placebo and nocebo responses for pain management. Curr Pain Headache Rep, 18(6), 419. doi:10.1007/s11916-014-0419-2

Cormier, S., Lavigne, G. L., Choinière, M., \& Rainville, P. (2016). Expectations predict chronic pain treatment outcomes. Pain, 157(2), 329-338.

Devilly, G. J., \& Borkovec, T. D. (2000). Psychometric properties of the credibility/expectancy questionnaire. J Behav Ther Exp Psychiatry, 31(2), 73-86.

Flor, H., Fydrich, T., \& Turk, D. C. (1992). Efficacy of multidisciplinary pain treatment centers: a meta-analytic review. Pain, 49(2), 221-230.

Gandhi, R., Davey, J. R., \& Mahomed, N. (2009). Patient expectations predict greater pain relief with joint arthroplasty. J Arthroplasty, 24(5), 716-721. doi:10.1016/j.arth.2008.05.016

Geurts, J. W., Willems, P. C., Lockwood, C., van Kleef, M., Kleijnen, J., \& Dirksen, C. (2017). Patient expectations for management of chronic non-cancer pain: A systematic review. Health Expect, 20(6), 1201-1217. doi:10.1111/hex.12527

Guttman, L. (1945). A basis for analyzing test-retest reliability. Psychometrika, 10, 255-282.

Hinkle, D. E. (2003). Applied Statistics for the Behavioral Sciences (5th edition ed.). Boston, USA: Houghton Mifflin. 
International Association for the Study of Pain. (1990). Task Force on Guidelines for Desirable Characteristics for Pain Treatment Facilities. Desirable characteristics for pain treatment facilities. Retrieved from http://www.iasp-pain.org/desirabl.html

Jonsdottir, T., Aspelund, T., Jonsdottir, H., \& Gunnarsdottir, S. (2014). The relationship between chronic pain pattern, interference with life and health-related quality of life in a nationwide community sample. Pain Manag Nurs, 15(3), 641-651. doi:10.1016/j.pmn.2013.07.005

Kline, P. (2000). The handbook of psychological testing (2nd edition ed.). London, UK: Routeledge.

Kravitz, R. L. (1996). Patients' expectations for medical care: an expanded formulation based on review of the literature. Med Care Res Rev, 53(1), 3-27.

Kroenke, K., Spitzer, R. L., Williams, J. B., \& Lowe, B. (2009). An ultra-brief screening scale for anxiety and depression: the PHQ-4. Psychosomatics, 50(6), 613-621. doi:10.1176/appi.psy.50.6.613

Kube, T., Rief, W., \& Glombiewski, J. A. (2017). On the Maintenance of Expectations in Major Depression - Investigating a Neglected Phenomenon. Front Psychol, 8, 9. doi:10.3389/fpsyg.2017.00009

Langley, P., Muller-Schwefe, G., Nicolaou, A., Liedgens, H., Pergolizzi, J., \& Varrassi, G. (2010). The societal impact of pain in the European Union: health-related quality of life and healthcare resource utilization. J Med Econ, 13(3), 571-581. doi:10.3111/13696998.2010.516709

Lin, T. H. (2010). A comparison of multiple imputation with EM algorithm and MCMC method for quality of life missing data. Quality \& Quantity, 44, 277-287.

Linde, K., Witt, C. M., Streng, A., Weidenhammer, W., Wagenpfeil, S., Brinkhaus, B., .. . Melchart, D. (2007). The impact of patient expectations on outcomes in four randomized controlled trials of acupuncture in patients with chronic pain. Pain, 128(3), 264-271. doi:10.1016/j.pain.2006.12.006

Melzack, R., \& Casey, K. L. (1968). Sensory, motivational and central control determinants of pain: A new conceptual model. In D. Kenshalo (Ed.), The Skin Senses (pp. 423-443). Springfield, IL: Thomas.

Mokken, R. J. (1971). A Theory and Procedure of Scale Analysis. The Hague, Netherlands: Mouton.

Molenaar, I. W., \& Sijtsma, K. (1984). Internal consistency and reliability in Mokken's nonparametric item response model. . Tijdschrift voor Onderwijsresearch, 9(5), 257-268.

Nicholas, M. K. (2007). The pain self-efficacy questionnaire: Taking pain into account. Eur J Pain, 11(2), 153-163. doi:10.1016/j.ejpain.2005.12.008

Pain, I. A. f. t. S. o. (1986). Classification of chronic pain. Descriptions of chronic pain syndromes and definitions of pain terms. PAIN, Suppl 3, S1-S225.

Peerdeman, K. J., van Laarhoven, A. I., Keij, S. M., Vase, L., Rovers, M. M., Peters, M. L., \& Evers, A. W. (2016). Relieving patients' pain with expectation interventions: a meta-analysis. Pain, 157(6), 1179-1191. doi:10.1097/j.pain.0000000000000540

PROMIS Validity Standards Committee on behalf of the PROMIS Network of Investigators. (2012). The PROMIS Instrument Development and Psychometric Evaluation Scientific Standards. Retrieved from www.nihpromis.org/science/methodology

R Core Team. (2017). R: A Language and Environment for Statistical Computing. Vienna, Austria: R Foundation for Statistical Computing. Retrieved from www.R-project.org

Revelle, W. (2018). psych: Procedures for psychological, psychometric, and personality research for $R$ version 1.8.10. Retrieved from http://CRAN.R-project.org/package=psych 
Revelle, W., \& Zinbarg, R. E. (2009). Coefficients alpha, beta, omega and the glb: comments on Sijtsma. Psychometrika, 74, 145-154. doi:10.1007/BF02293957

Robinson, M. E., Brown, J. L., George, S. Z., Edwards, P. S., Atchison, J. W., Hirsh, A. T., . . . Fillingim, R. B. (2005). Multidimensional success criteria and expectations for treatment of chronic pain: the patient perspective. Pain Med, 6(5), 336-345. doi:10.1111/j.15264637.2005.00059.x

Rotter, J. B. (1954). Social learning and clinical psychology. New York, NY: Prentice-Hall.

Rotter, J. B. (1982). The development and application of social learning theory. New York, NY: Praeger.

Scheier, M. F., \& Carver, C. S. (1985). Optimism, coping, and health: assessment and implications of generalized outcome expectancies. Health Psychol, 4(3), 219-247.

Scheier, M. F., Carver, C. S., \& Bridges, M. W. (1994). Distinguishing optimism from neuroticism (and trait anxiety, self-mastery, and self-esteem): a reevaluation of the Life Orientation Test. J Pers Soc Psychol, 67(6), 1063-1078.

Schopflocher, D., Taenzer, P., \& Jovey, R. (2011). The prevalence of chronic pain in Canada. Pain Research \& Management, 16, 445-450.

Sijtsma, K., \& van der Ark, L. A. (2017). A tutorial on how to do a Mokken scale analysis on your test and questionnaire data. Br J Math Stat Psychol, 70(1), 137-158. doi:10.1111/bmsp.12078

Thompson, A. G., \& Sunol, R. (1995). Expectations as determinants of patient satisfaction: concepts, theory and evidence. Int J Qual Health Care, 7(2), 127-141.

Van der Ark, L. A. (2007). Mokken Scale Analysis in R. Journal of Statistical Software, 20(11), 119.

van der Ark, L. A., Straat, J. H., \& Koopman, L. (2018). Conducts Mokken Scale Analysis: Package 'mokken' version 2.8.11. Retrieved from https://sites.google.com/a/tilburguniversity.edu/avdrark/mokken

van Hartingsveld, F., Ostelo, R. W., Cuijpers, P., de Vos, R., Riphagen, I. I., \& de Vet, H. C. (2010). Treatment-related and patient-related expectations of patients with musculoskeletal disorders: a systematic review of published measurement tools. Clin J Pain, 26(6), 470488. doi:10.1097/AJP.0b013e3181e0ffd3

Ware, J., Jr., Kosinski, M., \& Keller, S. D. (1996). A 12-Item Short-Form Health Survey: construction of scales and preliminary tests of reliability and validity. Medical Care, $34(3), 220-233$. 
Table 1. Preliminary items of the Treatment Expectations in Chronic Pain scale and details of the final item selection process

\begin{tabular}{ll}
\hline \multicolumn{1}{c}{ Items } & Status \\
\hline 1. My pain will be significantly reduced & Included \\
\hline 5. I will be able to do routine activities (cooking, cleaning, & Included \\
self-hygiene) better & \\
\hline 7. I will learn the reason for my pain & Included \\
\hline 8. I will receive a clear pain treatment plan & Included \\
\hline $\begin{array}{ll}\text { 14. I will learn about ways I can manage my pain condition } \\
\text { 16. I will learn more about my pain condition }\end{array}$ & Included \\
\hline $\begin{array}{l}\text { 17. My mood will significantly improve } \\
\text { 18. The pain specialist will understand my situation and all }\end{array}$ & Included \\
its challenges & \\
\hline 19. My sleep will significantly improve & Included \\
\hline 2. The pain specialist will treat me with respect, courtesy and & Removed - unscalable (H < \\
sensitivity & $0.3)$ \\
\hline 3. My quality of life will significantly improve & Removed-highly correlated \\
& with item \#1 \\
\hline 4. The pain specialist will be competent and thorough & Removed - unscalable (H< \\
& $0.3)$ \\
\hline
\end{tabular}




\begin{tabular}{ll}
\hline 9. I will take a more active role in my treatment plan & Removed - unscalable (H< \\
& $0.3)$ \\
\hline $\begin{array}{l}\text { 10. The pain specialist will consider my preferences when } \\
\text { planning my pain treatment }\end{array}$ & Removed - unscalable (H< \\
\hline 11. The symptoms related to my pain will significantly & Removed-highly correlated \\
decrease & with items \#13, 18 and 19 \\
\hline 12. This clinic is ideal for treating my pain condition & Removed - non- \\
& independence with items 17 \\
& and 18 \\
\hline 13. I will be pain free at the end of treatment & Removed - non- \\
& independence with item 18 \\
\hline 15. My level of functioning will significantly improve & Removed-highly correlated \\
& with items \#5, 11, and 19
\end{tabular}


Table 2. Descriptive statistics for the overall patient sample and scores on the ideal and predicted Treatment Expectations in Chronic Pain subscales

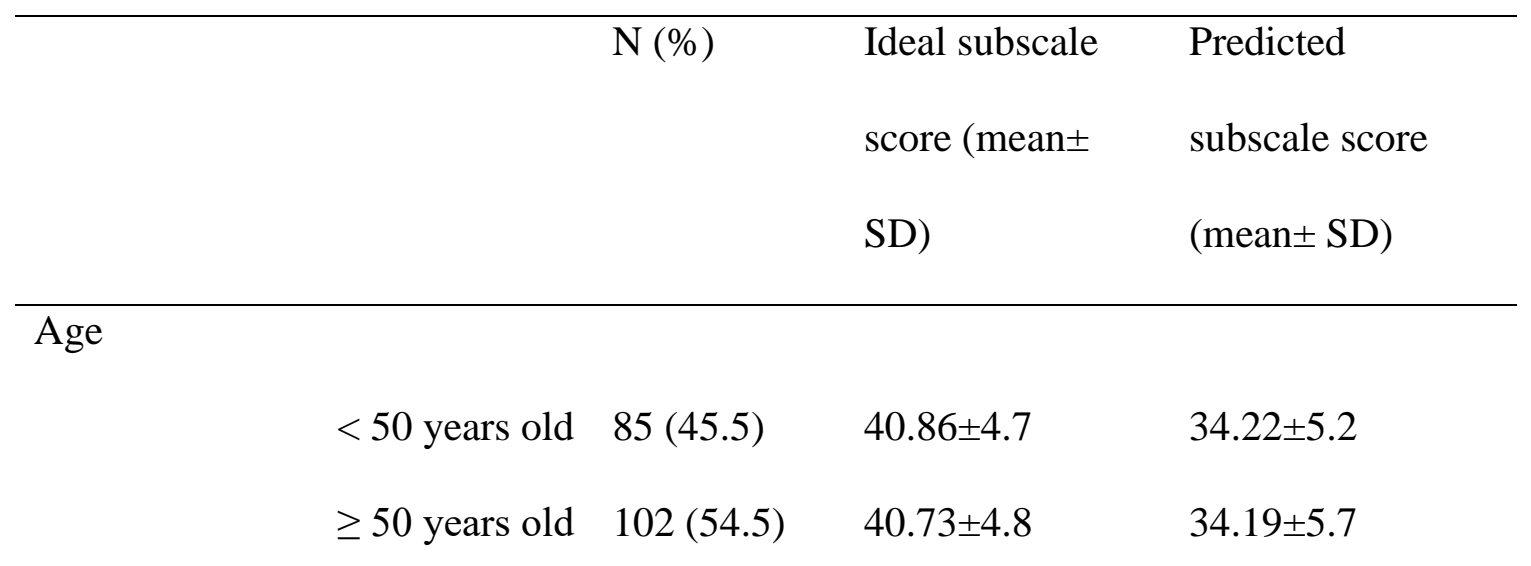

Sex

$\begin{array}{cccc}\text { Female } & 111(59.4) & 41.43 \pm 4.1 & 34.80 \pm 5.4 \\ \text { Male } & 76(40.6) & 39.74 \pm 5.4 & 33.33 \pm 5.4\end{array}$

Education

$\begin{array}{rrrr}\text { High school or less } & 57(30.5) & 40.93 \pm 5.0 & 34.07 \pm 5.6 \\ \text { More than high school } & 130(69.5) & 40.66 \pm 4.6 & 34.26 \pm 5.4\end{array}$

Ethnicity

$\begin{array}{rlrr}\text { Caucasian } & 155(82.9) & 40.94 \pm 4.6 & 34.26 \pm 5.6 \\ \text { Other } & 32(17.1) & 39.81 \pm 5.3 & 33.94 \pm 4.9\end{array}$

Work status

Working (full-time or part-time) $58(31.0) \quad 41.12 \pm 5.1 \quad 33.95 \pm 5.9$

Other $129(69.0) \quad 40.57 \pm 4.6 \quad 34.32 \pm 5.3$ 
Table 3. Scale properties

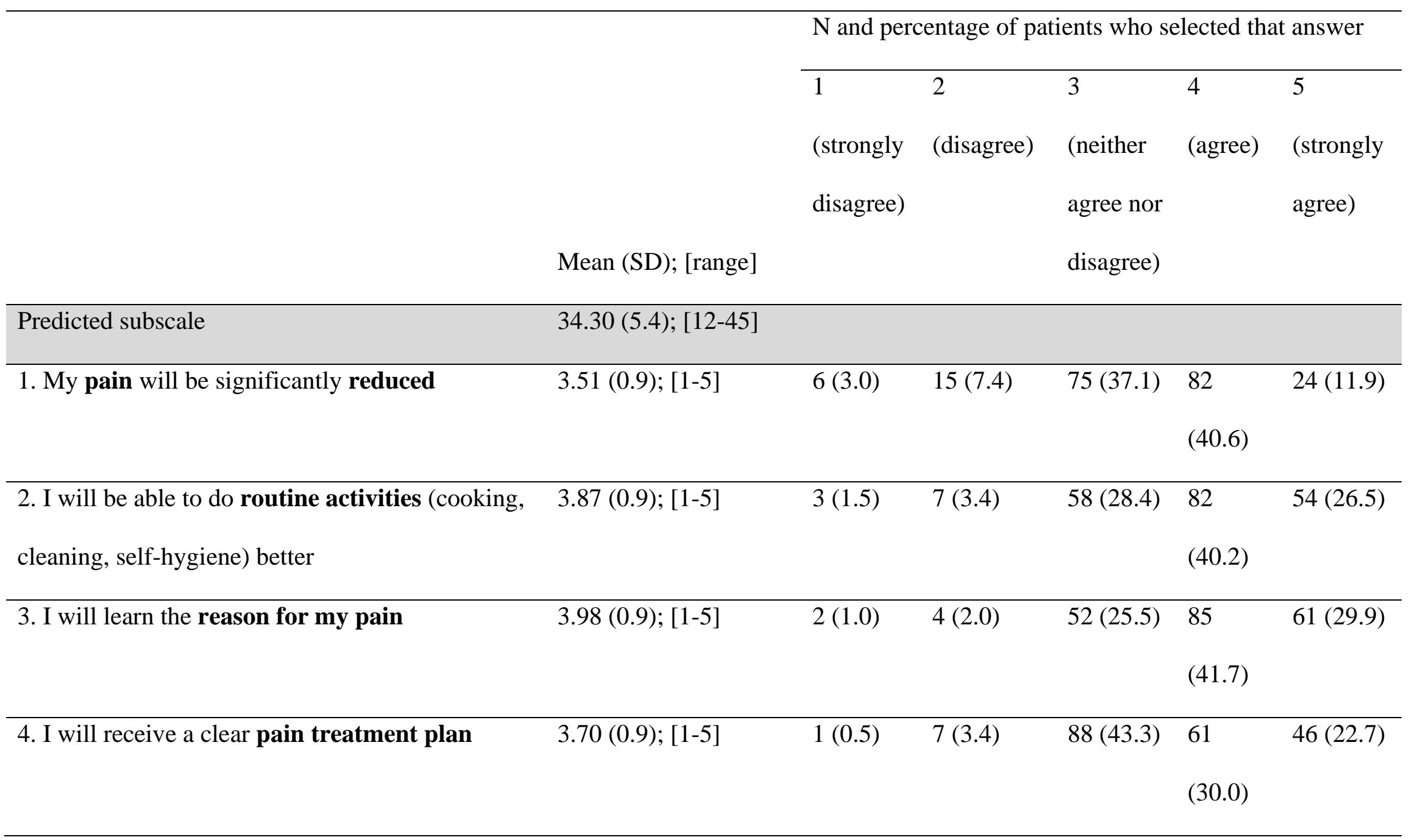




\begin{tabular}{|c|c|c|c|c|c|c|}
\hline $\begin{array}{l}\text { 5. I will learn about ways I can manage my pain } \\
\text { condition }\end{array}$ & $2.89(1.0) ;[1-5]$ & $19(9.5)$ & $42(20.9)$ & $94(46.8)$ & 34 & $12(6.0)$ \\
\hline $\begin{array}{l}\text { 8. The pain specialist will understand my } \\
\text { situation and all its challenges }\end{array}$ & 3.87 (0.9); [1-5] & $2(1.0)$ & $8(3.9)$ & $58(28.3)$ & $\begin{array}{l}85 \\
(41.5)\end{array}$ & $52(25.4)$ \\
\hline Ideal subscale & 40.90 (4.6); [21-45] & & & & & \\
\hline 1. My pain will be significantly reduced & $4.53(0.7) ;[1-5]$ & $1(0.5)$ & $3(1.5)$ & $13(5.9)$ & $\begin{array}{l}58 \\
(28.4)\end{array}$ & $\begin{array}{l}130 \\
(63.7)\end{array}$ \\
\hline $\begin{array}{l}\text { 2. I will be able to do routine activities (cooking, } \\
\text { cleaning, self-hygiene) better }\end{array}$ & $4.57(0.7) ;[2-5]$ & $0(0)$ & $2(1.0)$ & $13(6.3)$ & $\begin{array}{l}56 \\
(27.3)\end{array}$ & $\begin{array}{l}134 \\
(65.4)\end{array}$ \\
\hline
\end{tabular}




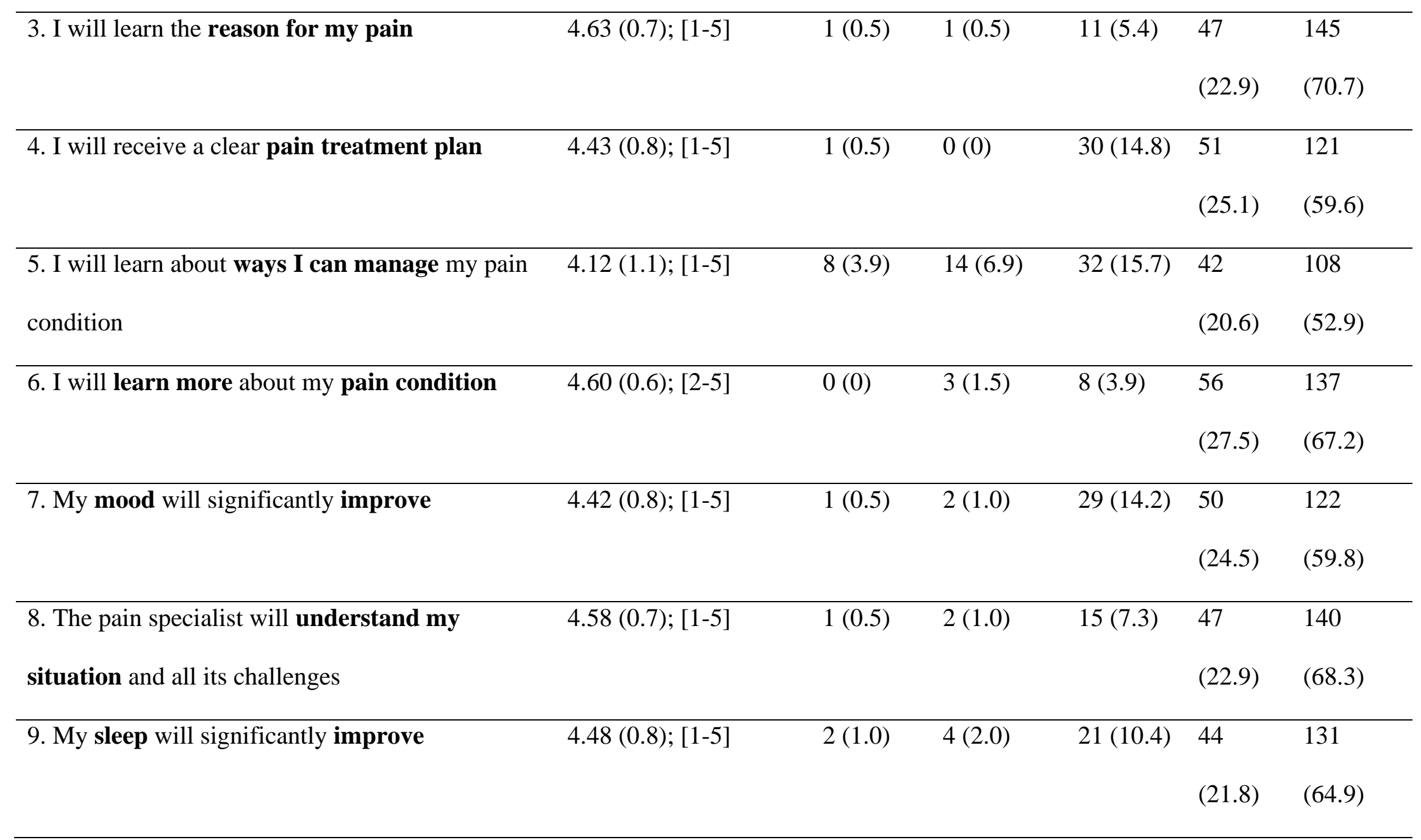


Table 4. Reliability of the Treatment Expectations in Chronic Pain Scale

\begin{tabular}{|c|c|c|c|c|}
\hline & $\begin{array}{l}\text { Corrected } \\
\text { item-total } \\
\text { correlation }\end{array}$ & $\begin{array}{l}\text { Cronbach's } \\
\text { alpha if item } \\
\text { deleted }\end{array}$ & $\begin{array}{l}\text { Cronbach's } \\
\text { alpha / } \\
\text { Guttman's } \\
\text { lambda }^{2}\end{array}$ & coefficient \\
\hline Predicted subscale & & & $0.869 / 0.872$ & 0.476 \\
\hline 1. My pain will be significantly reduced & 0.589 & 0.840 & & 0.496 \\
\hline $\begin{array}{l}\text { 2. I will be able to do routine activities (cooking, cleaning, self-hygiene) } \\
\text { better }\end{array}$ & 0.638 & 0.836 & & 0.478 \\
\hline 3. I will learn the reason for my pain & 0.549 & 0.844 & & 0.460 \\
\hline 4. I will receive a clear pain treatment plan & 0.595 & 0.840 & & 0.485 \\
\hline 5. I will learn about ways I can manage my pain condition & 0.523 & 0.846 & & 0.440 \\
\hline 6. I will learn more about my pain condition & 0.487 & 0.850 & & 0.421 \\
\hline 7. My mood will significantly improve & 0.647 & 0.835 & & 0.524 \\
\hline 8. The pain specialist will understand my situation and all its challenges & 0.558 & 0.843 & & 0.462 \\
\hline
\end{tabular}




\begin{tabular}{llll}
\hline 9. My sleep will significantly improve & 0.637 & 0.836 & 0.512 \\
Ideal subscale & & & $0.876 / 0.880$ \\
1. My pain will be significantly reduced & 0.580 & 0.868 & 0.452 \\
2. I will be able to do routine activities (cooking, cleaning, self-hygiene) & 0.584 & 0.868 & 0.445 \\
better & & & 0.422 \\
3. I will learn the reason for my pain & 0.568 & 0.871 & 0.479 \\
4. I will receive a clear pain treatment plan & 0.628 & 0.864 & 0.464 \\
5. I will learn about ways I can manage my pain condition & 0.582 & 0.869 & 0.483 \\
6. I will learn more about my pain condition & 0.644 & 0.863 & 0.518 \\
7. My mood will significantly improve & 0.660 & 0.862 & 0.535 \\
8. The pain specialist will understand my situation and all its challenges & 0.695 & 0.858 & 0.527 \\
9. My sleep will significantly improve & 0.670 & 0.861 & \\
\hline
\end{tabular}


Table 5. Pearson correlation coefficients between the Treatment Expectations in Chronic Pain subscales and measures of optimism, quality of life, anxiety and depression.

\begin{tabular}{|c|c|c|c|c|c|c|c|c|}
\hline & TEC_P & TEC_I & TEC_Diff & LOT-R & SF12_M & SF12_P & PHQ-A & PHQ-D \\
\hline TEC_P & $34.30(5.4)$ & & & & & & & \\
\hline TEC_I & $0.432 * *$ & $40.90(4.6)$ & & & & & & \\
\hline TEC_Diff & $0.628 * *$ & $-0.431 * *$ & $6.60(5.4)$ & & & & & \\
\hline LOT-R & $-0.240 * *$ & -0.061 & $0.208 * *$ & $9.92(5.4)$ & & & & \\
\hline SF12_M & 0.114 & -0.038 & -0.145 & $-0.488 * *$ & $38.81(12.6)$ & & & \\
\hline SF12_P & 0.089 & -0.024 & -0.114 & 0.009 & $-0.201 * *$ & $30.29(9.6)$ & & \\
\hline PHQ-A & 0.098 & 0.092 & -0.020 & $0.359 * *$ & $-0.628 * *$ & 0.079 & $3.35(2.0)$ & \\
\hline PHQ-D & -0.139 & -0.016 & 0.127 & $0.480 * *$ & $-0.743 * *$ & -0.044 & $0.614 * *$ & $2.85(2.0)$ \\
\hline \multicolumn{9}{|c|}{ Means and standard deviations are shown in the diagonal. TEC_P: Treatment Expectations in Chronic pain Predicted subscale; } \\
\hline \multicolumn{9}{|c|}{ TEC_I: Treatment Expectations in Chronic Pain Ideal subscale; TEC_Diff: Difference between ideal and predicted subscale score; } \\
\hline \multicolumn{9}{|c|}{ LOT-R: Life Orientation Test Revised; SF12_M: Short Form Health Survey 12 items version 2, mental health normed-based score; } \\
\hline SF12_P: Sho & Form Health & vey 12 item & ersion 2 , ph & ical health & ned-based sc & ; PHQ-A: P & ent Health & stionnaire-4 \\
\hline
\end{tabular}




\section{Supplementary material}

Supplementary Table 1. Test for the assumption of invariant ordering

Supplementary Table 2. Identification of Mokken subscales for the Treatment Expectations in Chronic Pain Scale using the AISP

Function

Supplementary Figure 1. Item response functions for each item. The left column represents the predicted expectation items and the right column represents the ideal expectation items. 
Supplementary Table 1 . Test for the assumption of invariant ordering

\begin{tabular}{lllllll}
\hline Item & Item H & \# ac & \# vi & \# vi/ac & maxvi & \#zsig \\
\hline $1 \mathrm{i}$ & 0.32 & 17408 & 81 & 0.00 & 0.09 & 29 \\
$1 \mathrm{r}$ & 0.37 & 17408 & 69 & 0.00 & 0.11 & 37 \\
$5 \mathrm{i}$ & 0.34 & 17408 & 77 & 0.00 & 0.10 & 38 \\
$5 \mathrm{r}$ & 0.37 & 17408 & 144 & 0.01 & 0.12 & 83 \\
$7 \mathrm{i}$ & 0.36 & 17408 & 74 & 0.00 & 0.08 & 36 \\
$7 \mathrm{r}$ & 0.37 & 17408 & 111 & 0.01 & 0.11 & 55 \\
$8 \mathrm{i}$ & 0.37 & 17408 & 72 & 0.00 & 0.09 & 40 \\
$8 \mathrm{r}$ & 0.39 & 17408 & 106 & 0.01 & 0.11 & 50 \\
$14 \mathrm{i}$ & 0.39 & 17408 & 100 & 0.01 & 0.11 & 45 \\
$14 \mathrm{r}$ & 0.38 & 17408 & 31 & 0.00 & 0.08 & 16 \\
$16 \mathrm{i}$ & 0.37 & 17408 & 85 & 0.00 & 0.11 & 47 \\
$16 \mathrm{r}$ & 0.36 & 17408 & 46 & 0.00 & 0.07 & 20 \\
$17 \mathrm{i}$ & 0.38 & 17408 & 71 & 0.00 & 0.11 & 44 \\
\hline & & & & & & \\
\hline
\end{tabular}




\begin{tabular}{lcccccc}
\hline $17 \mathrm{r}$ & 0.44 & 17408 & 64 & 0.00 & 0.08 & 38 \\
$18 \mathrm{i}$ & 0.42 & 17408 & 102 & 0.01 & 0.11 & 61 \\
$18 \mathrm{r}$ & 0.37 & 17408 & 118 & 0.01 & 0.12 & 63 \\
$19 \mathrm{i}$ & 0.36 & 17408 & 96 & 0.01 & 0.12 & 54 \\
$19 \mathrm{r}$ & 0.44 & 17408 & 25 & 0.00 & 0.05 & 12 \\
\hline
\end{tabular}

Note : ac: active comparisons; vi: violations; maxvi : maximum size of a violation reported;\# zsig: number of significant violations 
Supplementary Table 2. Identification of Mokken subscales for the Treatment Expectations in Chronic Pain Scale using the AISP Function

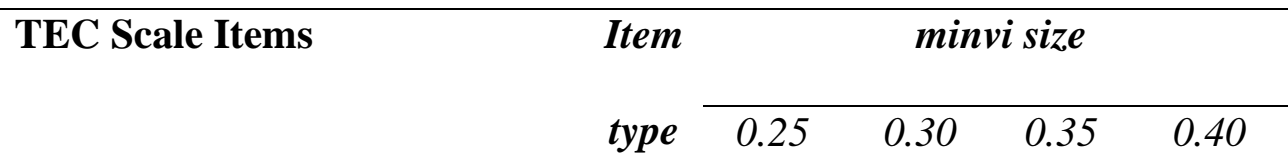

1p. My pain will be significantly reduced

$\begin{array}{lllll}\mathrm{O} & 1 & 1 & 1 & 1\end{array}$

1i. My pain will be significantly reduced

$\begin{array}{lllll}\mathrm{O} & 1 & 1 & 2 & 2\end{array}$

5p. I will be able to do routine activities (cooking,

$\begin{array}{lllll}\mathrm{O} & 1 & 1 & 1 & 1\end{array}$

cleaning, self-hygiene) better

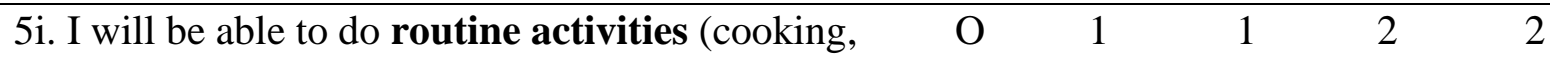
cleaning, self-hygiene) better

$7 \mathrm{p}$. I will learn the reason for my pain

$\begin{array}{lllll}\mathrm{O} & 1 & 1 & 1 & 1\end{array}$

7i. I will learn the reason for my pain

$\begin{array}{lllll}\mathrm{O} & 1 & 1 & 2 & 2\end{array}$

\begin{tabular}{llllll}
\hline 8p. I will receive a clear pain treatment plan & $\mathrm{P}$ & 1 & 1 & 1 & 1 \\
\hline 8i. I will receive a clear pain treatment plan & $\mathrm{P}$ & 1 & 1 & 2 & 2
\end{tabular}

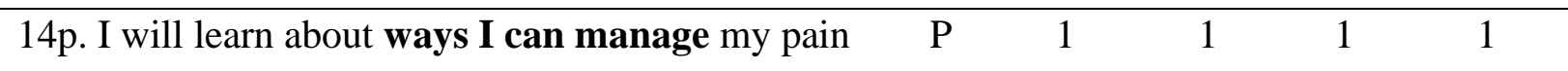
condition

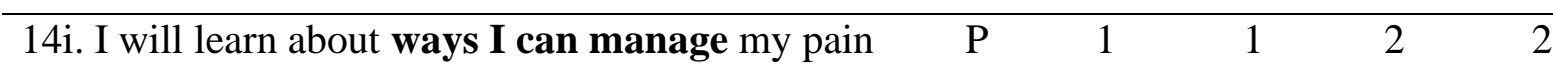
condition

\begin{tabular}{lccccc}
\hline 16p. I will learn more about my pain condition & $\mathrm{P}$ & 1 & 1 & 1 & 1 \\
\hline 16i. I will learn more about my pain condition & $\mathrm{P}$ & 1 & 1 & 2 & 2 \\
\hline 17p. My mood will significantly improve & $\mathrm{O}$ & 1 & 1 & 1 & 1 \\
\hline 17i. My mood will significantly improve & $\mathrm{O}$ & 1 & 1 & 2 & 2
\end{tabular}




\begin{tabular}{|c|c|c|c|c|c|}
\hline $\begin{array}{l}\text { 18p. The pain specialist will understand } \mathbf{m y} \\
\text { situation and all its challenges }\end{array}$ & $\mathrm{P}$ & 1 & 1 & 1 & 1 \\
\hline $\begin{array}{l}\text { 18i. The pain specialist will understand } \mathbf{m y} \\
\text { situation and all its challenges }\end{array}$ & $\mathrm{P}$ & 1 & 1 & 2 & 2 \\
\hline 19p. My sleep will significantly improve & $\mathrm{O}$ & 1 & 1 & 1 & 1 \\
\hline 19i. My sleep will significantly improve & $\mathrm{O}$ & 1 & 1 & 2 & 2 \\
\hline
\end{tabular}

Note: O: outcome expectation; P: process expectation; p: predicted expectation; i: ideal expectation; TEC scale: Treatment Expectations in Chronic Pain Scale 


\section{Predicted Expectations}

1. My pain will be significantly reduced
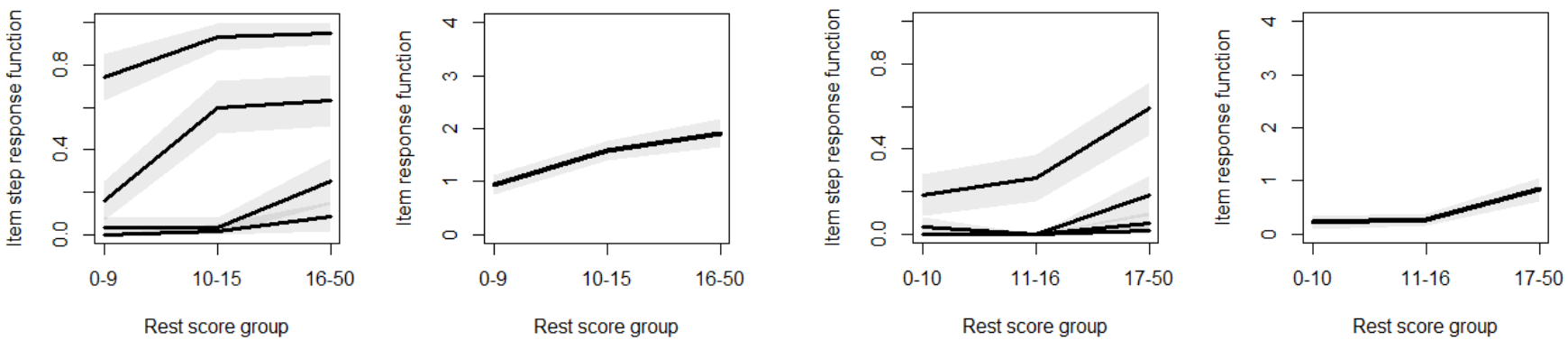

2. I will be able to do routine activities (cooking, cleaning, self-hygiene) better
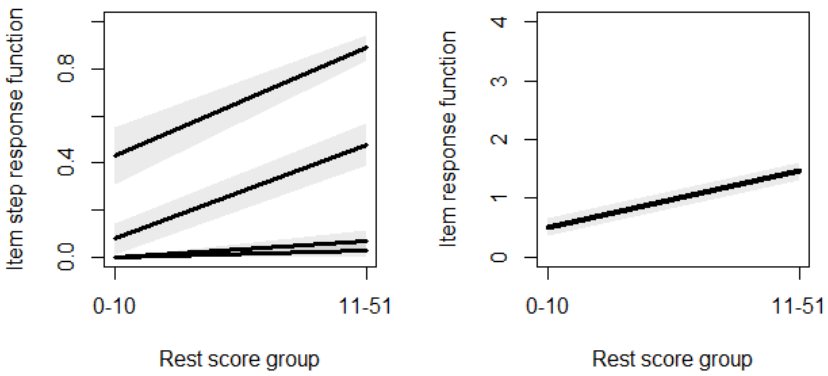

3. I will learn the reason for my pain
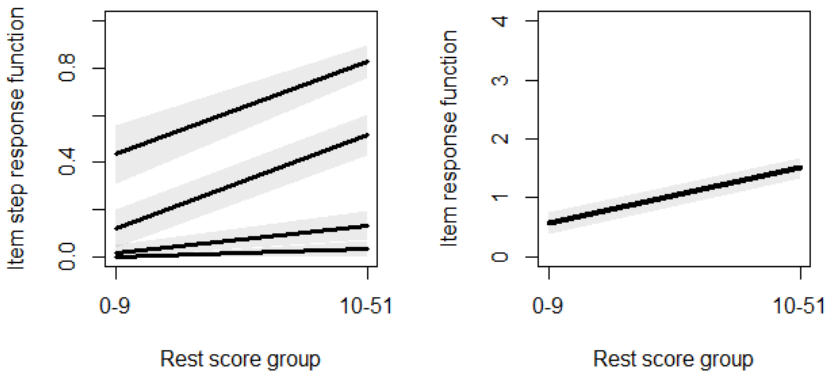

4. I will receive a clear pain treatment plan
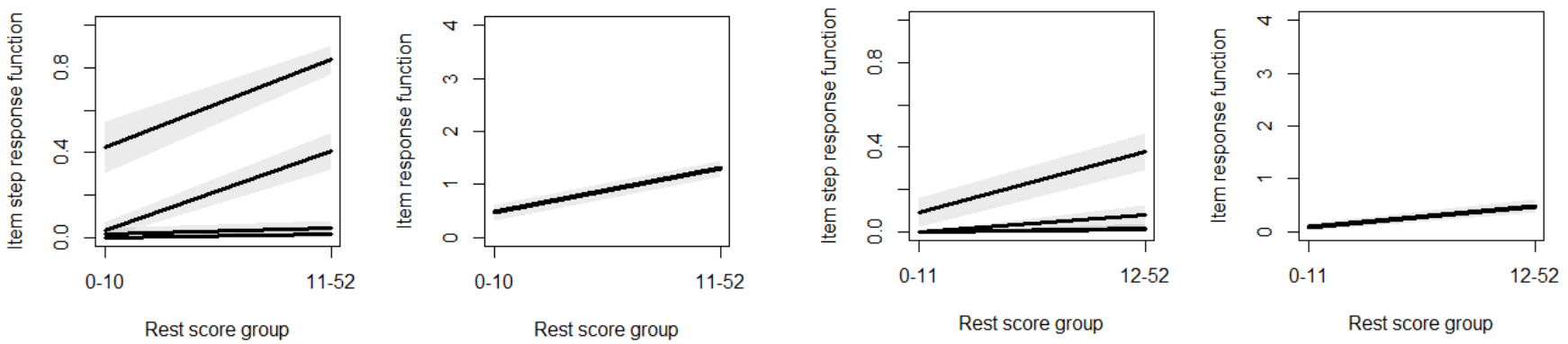


\section{Predicted Expectations}

5. I will learn about ways I can manage my pain condition
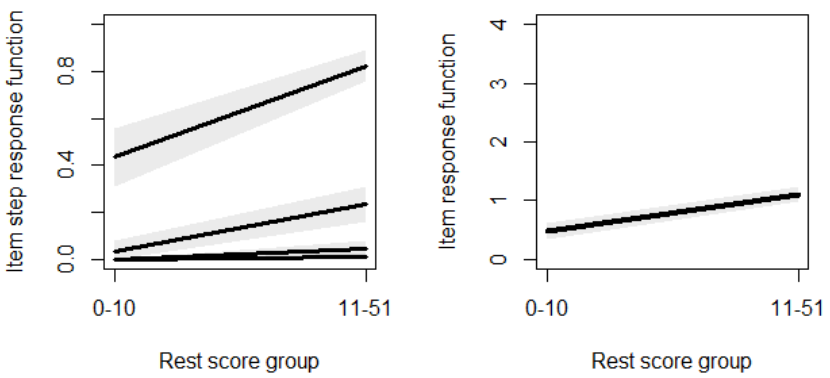

6. I will learn more about my pain condition
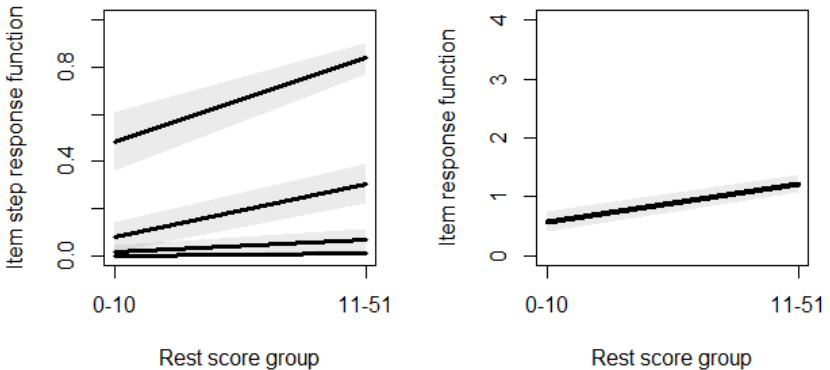

7. My mood will significantly improve
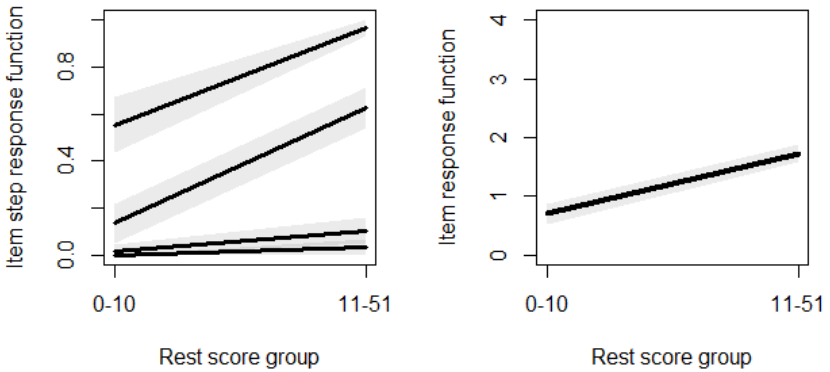

8. The pain specialist will understand my situation and all its challenges

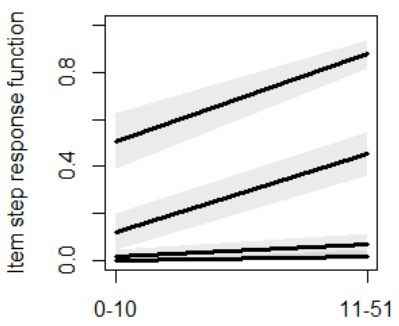

Rest score group

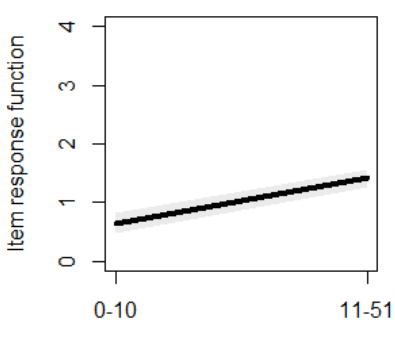

Rest score group
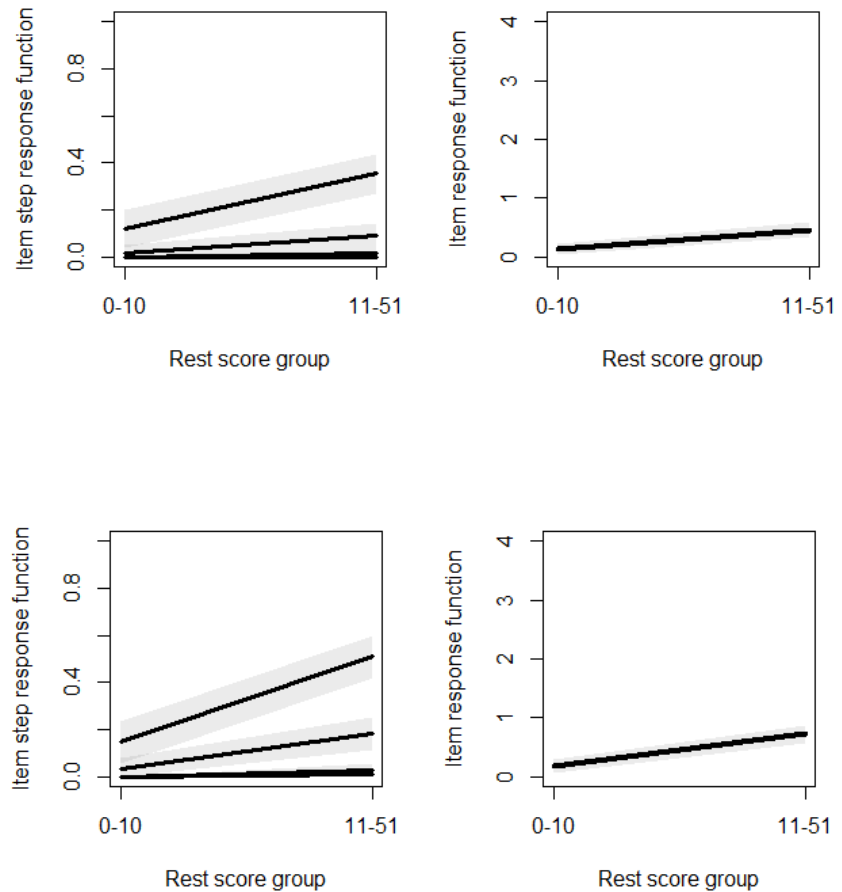

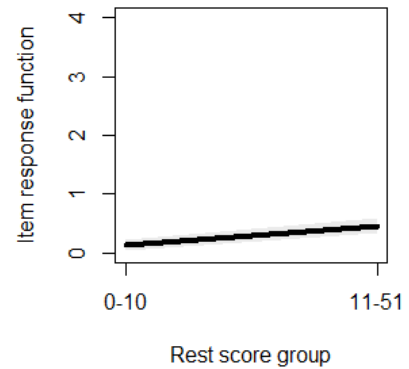

Rest score group

9. My sleep will significantly improve

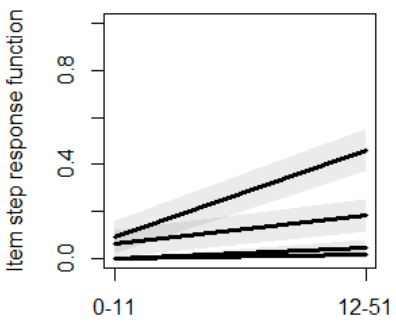

Rest score group

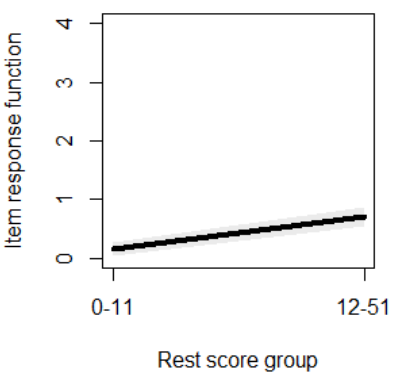

Rest score group

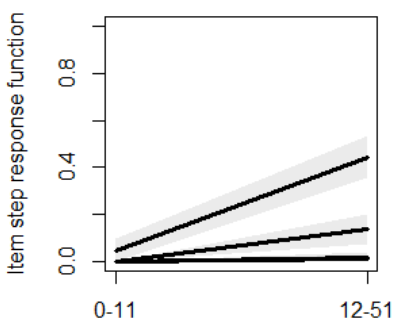

Rest score group

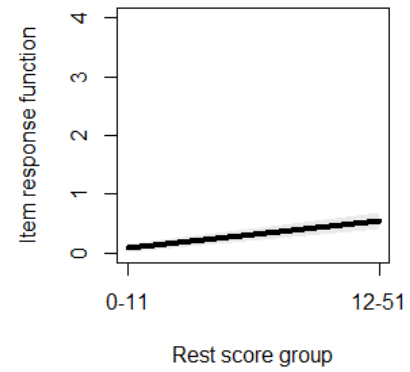

